\title{
EVALUATION OF SHRINKAGE BEHAVIOR OF SOME MAJOR COMMERCIAL SINGLE KNIT STRUCTURES KNITTED WITH COTTON AND COTTON/POLYESTER BLENDED YARNS
}

\section{A. K. M. MOBAROK HOSSAIN}

Assistant Professor, Department of Textile Engineering, Ahsanullah University of Science and Technology, Bangladesh

\begin{abstract}
Some major single jersey structures knitted with cotton and cotton/polyester blended yarns at same knitting variables were subjected to simple wet processing and effects of structural variation, fiber blends (as on yarn) on shrinkage and areal density were observed. Results showed that polyester content in yarn results in reduced residual shrinkage and higher areal density on wet-treated fabric. For all structures, dimensional changes were negative in lengthwise and positive in widthwise, indicating greater consolidation effect during the experimental study. Tuck loop based structures showed higher areal density than all knit one. Concerning dimensional changes and performances, the experimental structures, i.e., single jersey plain, single lacoste, double lacoste and double cross tuck may be individually judged for particular application in knitted clothing. KEYWORDS: Knitted Fabric, Areal Density, Shrinkage, Consolidation, Wet Processing, Relaxation \& Reference State
\end{abstract}

Received: Jul 14, 2017; Accepted: Aug 04, 2017; Published: Aug 21, 2017; Paper Id.: IJTFTAUG20176

\section{INTRODUCTION}

Shrinkage is an inherent characteristic of knitted fabric, which results in dimensional changes in fabric as well as in stitches. It affects the fit of a garment and also can account for seam puckering, torqueing or stitch distortion. The modern fashion trend in knitted articles like pants, tights and sportswear, has open the scope for application of a variety of knitted structures created with yarns of different types and fiber blends. Shrinkage is regarded as the most critical quality issue to be controlled by a knitter or finisher as it is directly interrelated with other major quality parameters, like areal density.

Generally, major part of shrinkage occurs during wet processing ${ }^{[1]}$. Tighter fabric results in higher width and lower length shrinkage during laundering ${ }^{[2]}$.However, acceptable shrinkage values can be achieved by a combination of careful yarn selection and controlled knitting and finishing procedures ${ }^{[3]}$.

\section{OBJECTIVES}

- To study shrinkage behavior of some major commercial single knit structures produced with cotton \& cotton/polyester blended yarns maintaining same major knitting variables, i.e. yarn count, stitch or loop length and machine).

- To observe the variation in areal density i.e. Grams per Square Meter (GSM) of fabric while evaluating shrinkage performance.

- To analyze the obtained data for determining qualitative/quantitative influence of test structures and fiber blends on obtained fabric GSM and shrinkage values. 


\section{MATERIALS AND METHODS}

\section{Source of Data}

Primary data was collected through practical work. An experimental study was carried out for a period of six months (January 16 to June 16) on a circular knitting machine (24-gauge and 10-inch dia.) in the knitting laboratory of Ahsanullah University of Science and Technology, Dhaka, Bangladesh. Wet processing facility was provided by Padma Polycotton Knit Fabrics Limited, a nearby knit composite factory at Tejgaon, Dhaka.

\section{Experimental Procedure}

\section{Knitting}

Knitted fabrics were produced by varying yarn type and loop length for four different single knit structures i.e. single jersey plain, single lacoste, double lacoste and double cross tuck.

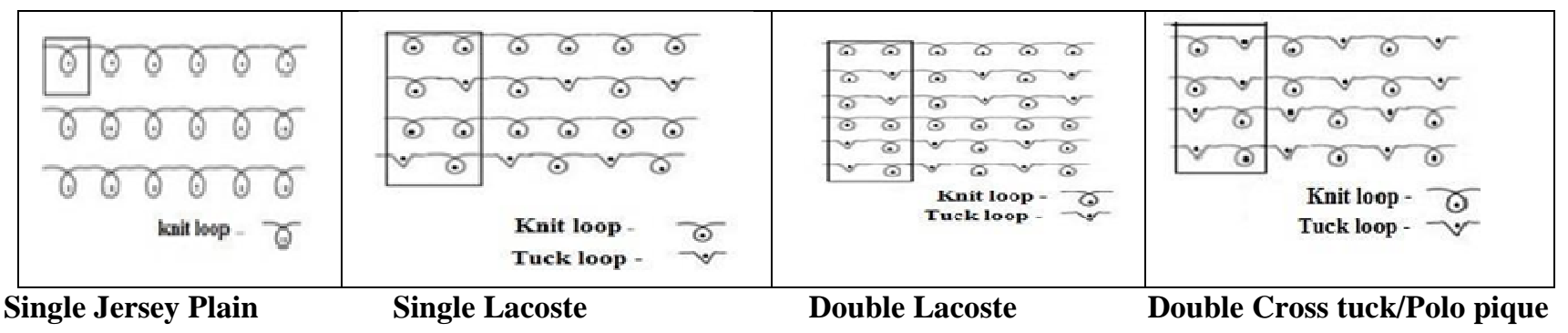

Figure 1

A total of 60 (sixty) styles were developed using 30/1 Ne CC( Combed Cotton) Cotton, 30/1Ne CVC( Cotton$60 \%$,Polyester-40\%), and 30/1Ne PC(Polyester-65\%,Cotton-35\%) at stitch lengths of $2.6 \mathrm{~mm}, 2.75 \mathrm{~mm}, 2.9 \mathrm{~mm}, 3.05 \mathrm{~mm}$, and $3.2 \mathrm{~mm}$ respectively.

\section{Wet Processing}

Samples of same quantity (around $0.4 \mathrm{~kg}$ each) were collected from grey fabrics for each specification, and these were subjected to wet treatment (scouring, bleaching with optical brightening agent) simultaneously in a single bath.

Observation on Areal Density and Shrinkage

After wet treatment, areal density of samples was measured by GSM cutter following BS EN 12127:1998 ${ }^{[4]}$.

To obtain reference state, the wet-treated fabrics were subjected to Reference Relaxation Procedure $(\mathrm{RRP})^{[5]}$.YILMAK washing machine was used to carry out the washing cycles, and SIEMENS Tumble Dryer was used for the drying purpose.

Changes in fabric dimensions (length and widthwise) was measured by SDL ATLAS shrinkage template and rule following ISO 3759: $2007^{[6]}$.

Obtained results were then analyzed to evaluate areal density and shrinkage performance of different structures, knitted at different stitch lengths with cotton and cotton/polyester blended yarns. 


\section{RESULTS}

\section{The Effect of Fiber Blends (as on Yarn) on Areal Density of Different Structures}

The following table shows comparative increment or decrement in areal density from cotton to its blends (with polyester) for different single jersey structures.

Table 1: Yarn Wise Change in Areal Density for Different Structures

\begin{tabular}{|c|c|c|c|c|c|c|c|c|c|c|c|}
\hline \multirow[b]{3}{*}{ Fabric Type } & \multirow[b]{3}{*}{$\begin{array}{l}\text { Yarn } \\
\text { Type }\end{array}$} & \multicolumn{10}{|c|}{ Stitch Length (.Im) } \\
\hline & & \multicolumn{2}{|c|}{2.6} & \multicolumn{2}{|c|}{2.75} & \multicolumn{2}{|c|}{2.9} & \multicolumn{2}{|c|}{3.05} & \multicolumn{2}{|c|}{3.2} \\
\hline & & $\begin{array}{l}\text { GSSII After } \\
\text { Wet } \\
\text { Processing }\end{array}$ & $\begin{array}{l}\text { \% Change } \\
\text { in Areal } \\
\text { Density }\end{array}$ & $\begin{array}{l}\text { GSII After } \\
\text { Wet } \\
\text { Processing }\end{array}$ & $\begin{array}{l}\text { \% Change in } \\
\text { Areal Density }\end{array}$ & $\begin{array}{l}\text { GSII After } \\
\text { Wet } \\
\text { Processing }\end{array}$ & $\begin{array}{l}\text { \% Change in } \\
\text { Areal Density }\end{array}$ & $\begin{array}{l}\text { GSII After } \\
\text { Wet } \\
\text { Processing }\end{array}$ & $\begin{array}{l}\text { \% Change } \\
\text { in Areal } \\
\text { Density }\end{array}$ & $\begin{array}{l}\text { GSII After } \\
\text { Wet } \\
\text { Processing }\end{array}$ & $\begin{array}{l}\text { \% Change in } \\
\text { Areal } \\
\text { Density }\end{array}$ \\
\hline \multirow{3}{*}{$\begin{array}{l}\text { Single Jessey } \\
\text { plaim }\end{array}$} & $301 \mathrm{CC}$ & 165.35 &. & 154.7 & . & 144.15 & . & 141.45 &. & 130.95 &. \\
\hline & $3011 \mathrm{CVC}$ & 165.6 & 0.15 & 155.5 & 0.52 & 145.95 & 1.25 & 143.5 & 1.45 & 135.6 & 3.55 \\
\hline & $3011 \mathrm{PC}$ & 170.55 & 3.14 & 159 & 2.78 & 156.05 & 8.25 & 147.75 & 4.45 & 137.95 & 5.34 \\
\hline \multirow{3}{*}{ Single Lacoste } & $301 \mathrm{CC}$ & 170.5 & . & 161.36 & . & 151.8 & . & 142 & . & 134.65 & . \\
\hline & $301 \mathrm{CVC}$ & 176.9 & 3.75 & 166.65 & 3.28 & 152.3 & 0.33 & 144.5 & 1.76 & 136.65 & 1.48 \\
\hline & $3011 \mathrm{PC}$ & 180.93 & 6.12 & 167.08 & 3.54 & 156.6 & 3.16 & 153.5 & 8.01 & 138.5 & 2.86 \\
\hline \multirow{3}{*}{ Double cross tuck } & $301 \mathrm{CC}$ & 181.77 & . & 171.69 & $\cdot$ & 157.34 & $\cdot$ & 145.55 & $\cdot$ & 137.1 & $\cdot$ \\
\hline & $3011 \mathrm{CVC}$ & 187.05 & 2.90 & 172 & 0.18 & 158.45 & 0.7 & 153 & 5.12 & 144 & 5.03 \\
\hline & $301 \mathrm{PC}$ & 189.05 & 4 & 175.45 & 2.19 & 169.25 & 7.57 & 155.35 & 6.73 & 146.9 & 7.15 \\
\hline \multirow{3}{*}{ Double Lacoste } & $301 \mathrm{CC}$ & 200.6 & . & 188.38 & . & 173.55 & . & 165 & . & 155.2 & . \\
\hline & $301 \mathrm{CVC}$ & 201.1 & 0.25 & 189.81 & 0.76 & 178.65 & 2.94 & 166.6 & 0.97 & 156.8 & 1.03 \\
\hline & $301 \mathrm{PC}$ & 202.9 & 1.15 & 194.75 & 3.38 & 180 & 3.72 & 168.53 & 2.14 & 157.28 & 1.34 \\
\hline
\end{tabular}

Evaluating the data of table 1, it can be found that cotton fabric showed lowest GSM in the processed state, where PC fabric showed the highest one. This is because, more cotton content in the yarn results more mass loss during scouring. However, areal density values of cotton/polyester blended yarn knitted fabrics were always less than $10 \%$ higher than that of only cotton knitted fabrics. Areal density values were always negatively co-related with stitch length values.

\section{Determining Structure Wise Change in Areal Density for Different Fibre Blends (as on Yarn)}

The following table shows comparative increment or decrement in areal density from single jersey plain to other single jersey derivatives for different fiber blends.

Table 2: Structure Wise Change in Areal Density for Different Fiber Blends

\begin{tabular}{|c|c|c|c|c|c|c|c|c|c|c|c|}
\hline \multirow[b]{3}{*}{ Yarn Type } & \multirow[b]{3}{*}{ Fabric Type } & \multicolumn{10}{|c|}{ Stitch Length (Mm) } \\
\hline & & \multicolumn{2}{|c|}{2.6} & \multicolumn{2}{|c|}{2.75} & \multicolumn{2}{|c|}{2.9} & \multicolumn{2}{|c|}{3.05} & \multicolumn{2}{|c|}{3.2} \\
\hline & & $\begin{array}{l}\text { GSM After } \\
\text { Wet } \\
\text { Processing }\end{array}$ & $\begin{array}{c}\text { \% Change in } \\
\text { Areal } \\
\text { Density }\end{array}$ & $\begin{array}{l}\text { GSM After } \\
\text { Wet } \\
\text { Processing }\end{array}$ & $\begin{array}{c}\text { \% Change in } \\
\text { Areal } \\
\text { Density }\end{array}$ & $\begin{array}{l}\text { GSM After } \\
\text { Wet } \\
\text { Processing }\end{array}$ & $\begin{array}{c}\text { \% Change in } \\
\text { Areal } \\
\text { Density }\end{array}$ & $\begin{array}{l}\text { GSM After } \\
\text { Wet } \\
\text { Processing }\end{array}$ & $\begin{array}{c}\text { \% Change in } \\
\text { Areal } \\
\text { Density }\end{array}$ & $\begin{array}{l}\text { GSM After } \\
\text { Wet } \\
\text { Processing }\end{array}$ & $\begin{array}{c}\text { \% Change In } \\
\text { Areal } \\
\text { Density }\end{array}$ \\
\hline \multirow{4}{*}{$30 / 1 \mathrm{CC}$} & Single Jersey Plain & 165.35 & - & 154.7 & - & 144.15 & - & 141.45 & - & 130.95 & - \\
\hline & Single Lacoste & 170.5 & 3.11 & 161.36 & 4.30 & 151.8 & 5.31 & 142 & 0.39 & 134.65 & 2.82 \\
\hline & Double Cross tuck & 181.77 & 9.93 & 171.69 & 10.98 & 157.34 & 9.15 & 145.55 & 2.9 & 137.1 & 4.7 \\
\hline & Double Lacoste & 200.6 & 21.32 & 188.38 & 21.78 & 173.55 & 20.39 & 165 & 16.65 & 155.2 & 18.52 \\
\hline \multirow{4}{*}{$30 / 1 \mathrm{CVC}$} & Single Jersey Plain & 165.6 & - & 155.5 & - & 145.95 & - & 143.5 & $\cdot$ & 135.6 & - \\
\hline & Single Lacoste & 176.9 & 6.82 & 166.65 & 7.17 & 152.3 & 4.35 & 144.5 & 0.7 & 136.65 & 0.77 \\
\hline & Double Cross tuck & 187.05 & 12.93 & 172 & 10.61 & 158.45 & 8.56 & 153 & 6.62 & 144 & 6.19 \\
\hline & Double Lacoste & 201.1 & 21.44 & 189.81 & 22.06 & 178.65 & 22.4 & 166.6 & 16.1 & 156.8 & 15.63 \\
\hline \multirow{4}{*}{$30 / 1 \mathrm{PC}$} & Single Jersey Plain & 170.55 & - & 159 & - & 156.05 & - & 147.75 & - & 137.95 & - \\
\hline & Single Lacoste & 180.93 & 6.09 & 167.08 & 5.08 & 156.6 & 0.35 & 153.5 & 3.89 & 138.5 & 0.4 \\
\hline & Double Cross tuck & 189.05 & 10.85 & 175.45 & 10.34 & 169.25 & 8.46 & 155.35 & 5.14 & 146.9 & 6.49 \\
\hline & Double Lacoste & 202.9 & 18.97 & 194.75 & 22.48 & 180 & 15.35 & 168.53 & 14.06 & 157.28 & 14.01 \\
\hline
\end{tabular}


Evaluating the data of table 2, it can be seen that double lacoste showed the highest GSM, and single jersey plain showed the lowest after wet treatment, when yarn count and stitch length remain constant. Double cross tuck showed the second highest GSM. Variation in stitch density due to structural construction and wet treatment may be attributed for such phenomena in different fabrics. On a gross observation, it may be found that single lacoste showed around 5\%, double cross tuck showed around 10\% and double lacoste showed around 20\% higher GSM than single jersey plain fabric, when knitted with yarns of same linear density.

Dimensional Change Due to Variation in Yarn Content for Different Structures after Relaxation Treatment i.e. RRP

Diagrammatic Representation of Dimensional Change (\%) for Single Jersey Plain Structure

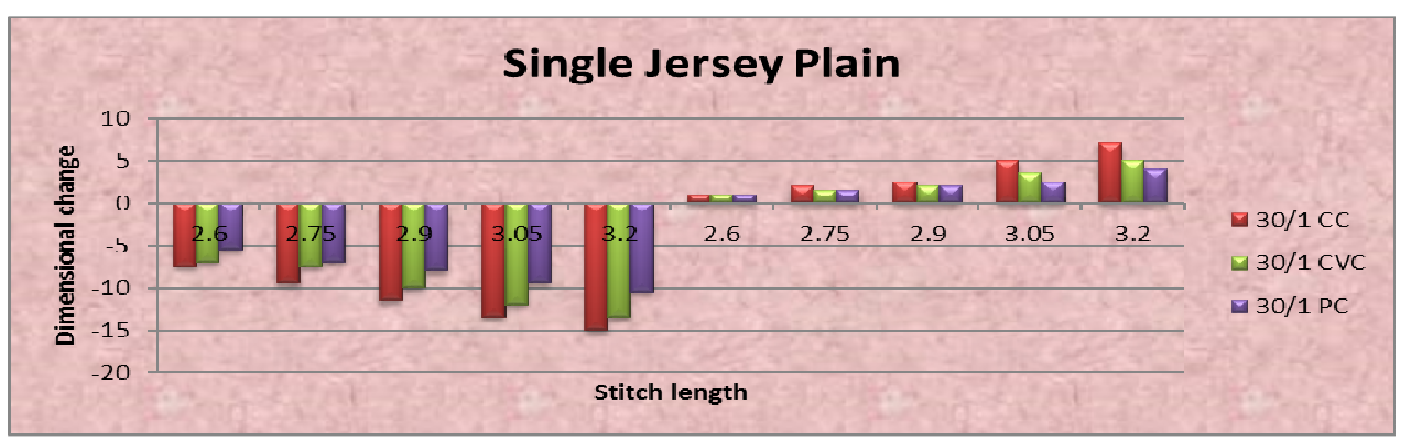

Figure 2: Change in Dimension after Relaxation Treatment Due to Yarn Composition for Single Jersey Plain Structure at different Stitch Length Values

Diagrammatic Representation of Dimensional Change (\%) for Single Lacoste Structure

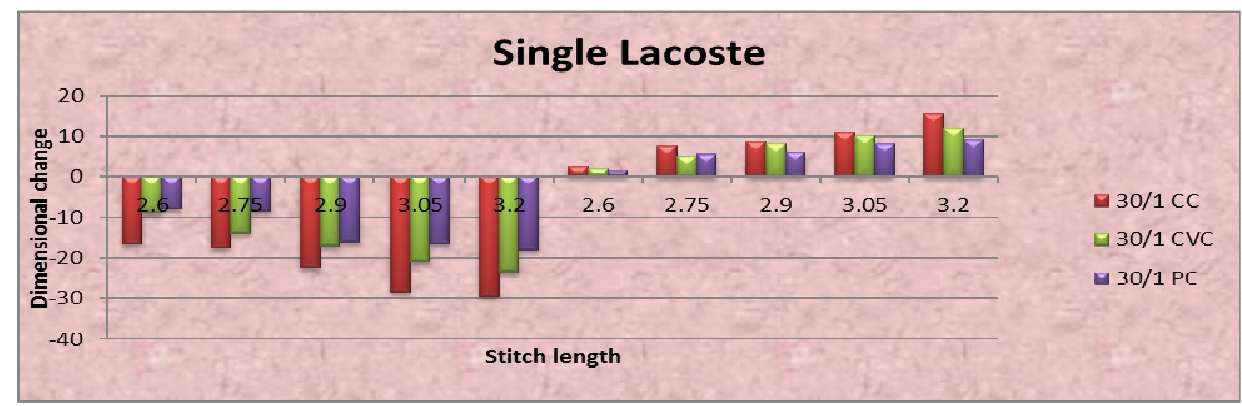

Figure 3: Change in Dimension after Relaxation Treatment Due to Yarn Composition for Single Lacoste Structure at Different Stitch Length Values

Diagrammatic Representation of Dimensional Change (\%) for Double Cross Tucks Structure

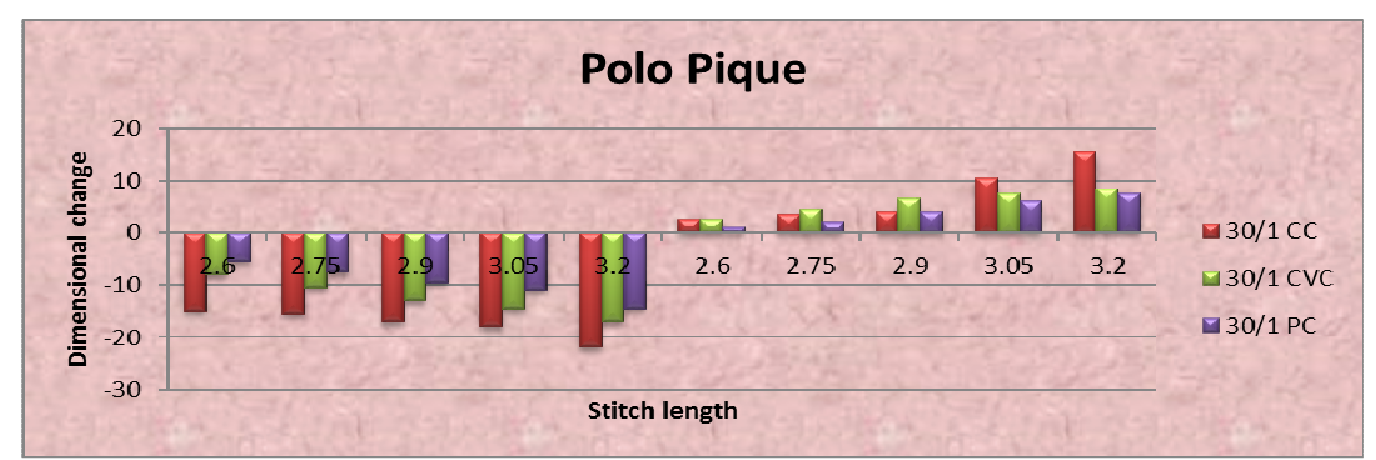

Figure 4: Change in Dimension after Relaxation Treatment Due to Yarn Composition for Polo Pique/ Double Cross Tuck Structure at Different Stitch Length Values 
Diagrammatic Representation of Dimensional Change (\%) for Double Lacoste Structure

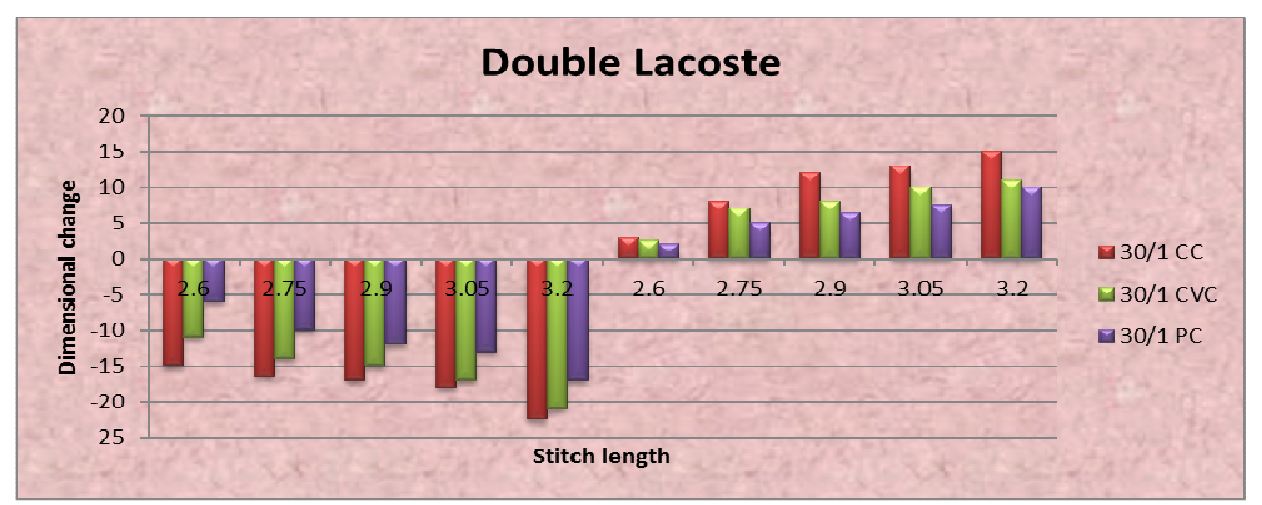

Figure 5: Change in Dimension after Relaxation Treatment Due to Yarn Composition for Double Lacoste Structure at Different Stitch Length Values

Lengthwise shrinkage \& widthwise expansion after the reference relaxation procedure [Fig.1-Fig.4] were observed for all structures. In most cases, dimensional changes (both in lengthwise \& widthwise) were highest in cotton fabrics \& lowest in PC fabrics. It may be assumed that vigorous wash \& dry cycles brought consolidation in yarn structure, which was responsible for positive dimensional change in width direction.

Dimensional Change Due to Structural Variation for Different Fibre Blends on Yarm For Fabrics Knitted with 30/1Ne Cotton Yarn

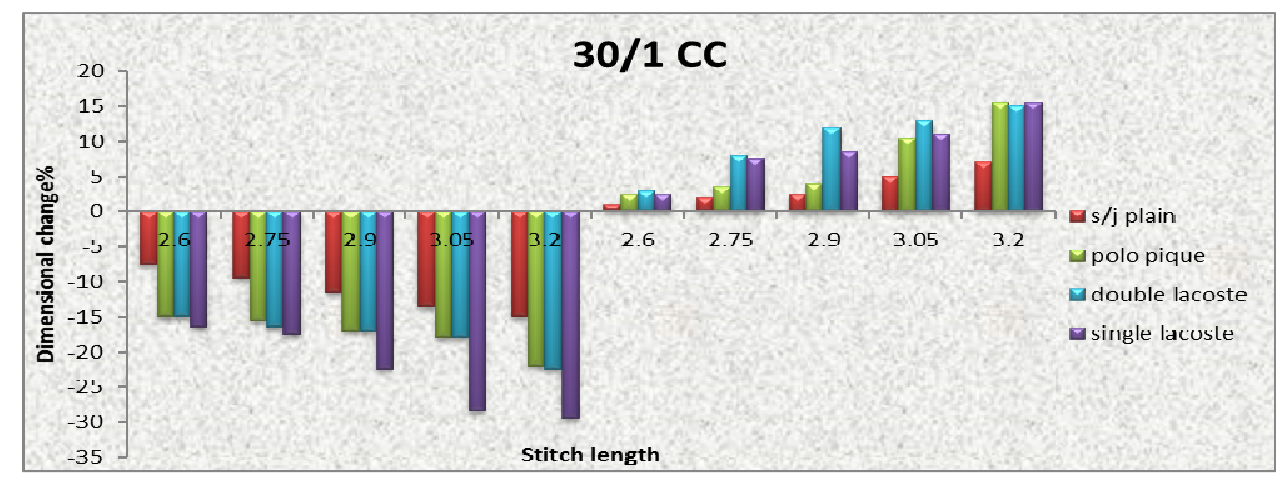

Figure 6: Change in Dimension after Relaxation Treatment Due to Structural Variation for 30/1 Ne Cotton at Different Stitch Length Values

For Fabrics Knitted With 30/1Ne CVC Yarn

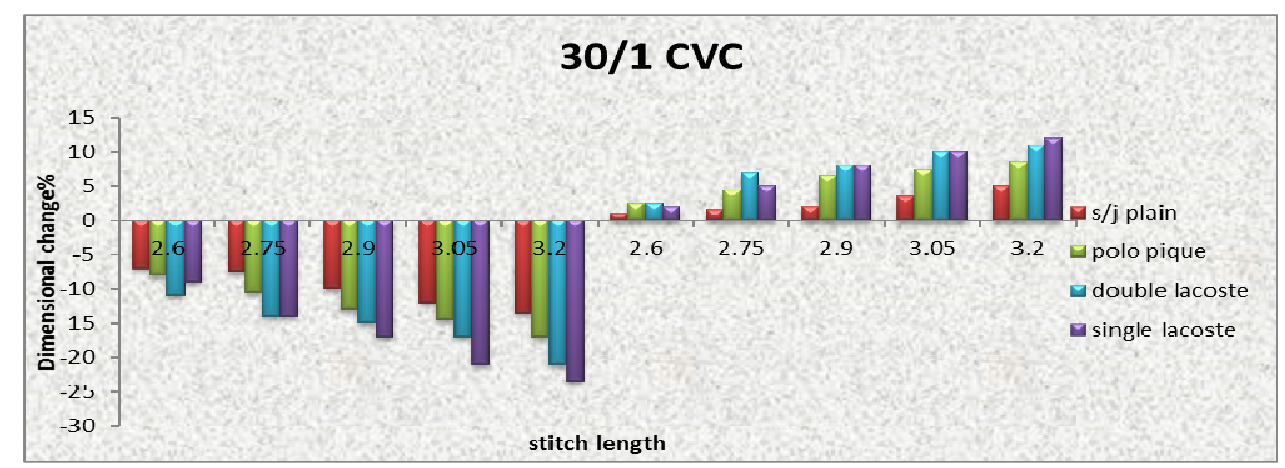

Figure 7: Change in Dimension after Relaxation Treatment Due to Structural Variation for 30/1 Ne CVC at Different Stitch Length Values 


\section{For Fabrics Knitted with 30/1Ne PC Yarn}

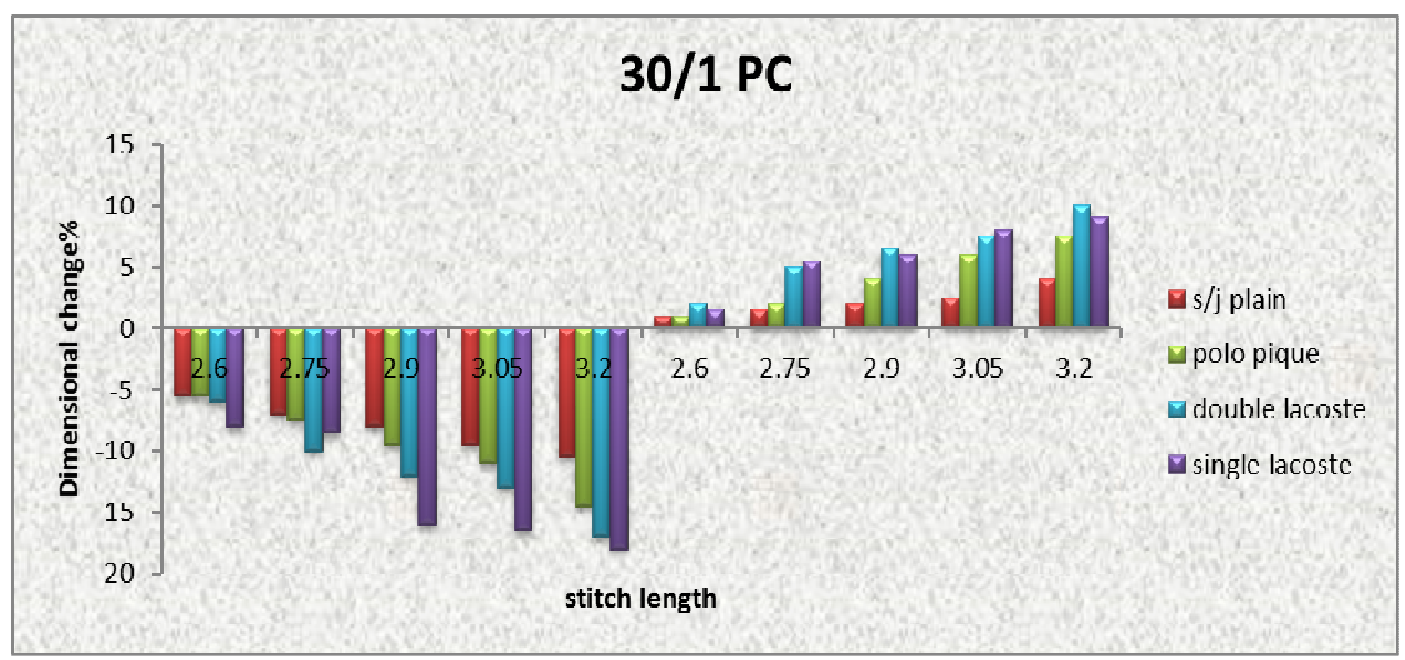

Figure 8: Change in Dimension after Relaxation Treatment Due to Structural Variation for 30/1 Ne PC at Different Stitch Length Values

A deep observation on Fig.5-Fig.7 reveals that for a particular structure, higher loop length causes greater dimensional change (either positively or negatively) after relaxation treatment, when yarn count remains unchanged. It may be noted that for negative dimensional change (i.e., shrinkage), a trend was observed among different structures. Single lacoste showed the highest shrinkage values, while single jersey plain showed the lowest. Double lacoste structure stands in $2^{\text {nd }}$ position. No such trend was found, while evaluating dimensional change in width direction, however, single jersey plain always showed lowest change, through expansion (i.e. negative shrinkage) among all structures.

\section{CONCLUSIONS}

Knitted fabrics produced from cotton/polyester blended yarns showed higher areal density than cotton knitted fabrics, after the scouring and bleaching process, though the fabrics were knitted using similar knitting variables (i.e. yarn count, stitch length, and number of needles). This is because, higher percentage of cotton results more mass loss due to scouring. Double lacoste structure showed highest GSM and single jersey plain showed the lowest. The presence of tuck loops increases fabric GSM, but the quantity and relative positioning of tuck loops in the structural repeat result variation in areal density among different knit-tuck based structures.

A comparative study of fabrics knitted from $100 \%$ cotton and cotton/polyester blended yarns revealed that blended fabrics shrink less. This might be attributed to the bulkier characteristics of blended yarns as well as the polyester fibers, which are less prone to shrinkage. CVC fabrics shrinks more than PC ones, because of higher amount of cotton content.

For all structures, negative dimensional change (i.e. shrinkage) was observed in lengthwise direction, whereas width expanded. It may be assumed that consolidation effect, which increases yarn diameter, was greater than relaxation effect in the width direction and so negative shrinkage occurred. However, a trend was observed in the lengthwise dimensional change (i.e. shrinkage). Single Lacoste showed the highest shrinkage value, where single jersey plain showed the lowest. 


\section{ACKNOWLEDGEMENT}

The present work was supported by the Department of Textile Engineering of Ahsanullah University of Science and Technology and Padma Polycotton Knit Fabrics Limited. The author would like to thank the lab assistants and employees of the concerned organizations.

\section{REFERENCES}

1. Collins G.E. (1939). Fundamental principles that govern the shrinkage of cotton goods by washing, Journal of the Textile Institute Proceedings, 30 (3), 46-61.

2. Onal L., Candan C. (2003). Contribution of fabric characteristics and laundering to shrinkage of weft knitted fabrics, Textile Research Journal, 73(3):187-191.

3. Suh M.W. (1967). A study of the shrinkage of plain knitted cotton fabric, based on the structural changes of the loop geometry due to yarn swelling \& deswelling, Textile Research Journal, 37(5):417-431.

4. BS EN $12127: 1998$, Textiles-Fabrics-Determination of mass per unit area using small samples

5. The STARFISH approach to high quality cotton knit goods, User Manual Version88:1, Cotton Technology International, UK, 1988.

6. ISO 3759:2007, Preparation, marking and measuring of fabric specimens and garments in test for determination of dimensional change. 
